\title{
Impact of global warming on the energetics of lower tropospheric ultra-long waves and the Indian summer monsoon
}

\author{
M D Chipade*, J R Kulkarni and S M Bawiskar \\ Indian Institute of Tropical Meteorology, Dr. Homi Bhabha Road, Pune 411 008, India. \\ ${ }^{*}$ Corresponding author. e-mail: mukundchipade@yahoo.co.in
}

\begin{abstract}
Analyses of 60 years (1949-2008) of monthly energetics of the zonal waves derived from NCEP/NCAR data indicate that ultra-long waves (waves 1 and 2) dominate the spectrum of lower tropospheric zonal waves during monsoon season (June-September). Westerlies over the Indian subcontinent are a source of energy to wave 1. Two oceanic anticyclones, one over Pacific and the other over Atlantic are sources of energy to wave 2. These two waves are inversely correlated. Climatology of the energetics of ultralong waves for the two epochs 1949-1978 (CLP1) and 1979-2008 (CLP2) of 30 years indicates that the intensity of wave 1 has decreased by about $33 \%$ whereas the intensity of wave 2 has increased by about 27\%. Northward transport of sensible heat during CLP1 changes to southward during CLP2. Larger generation of zonal mean Available Potential Energy (APE) during CLP2 indicates more heating. A larger conversion of kinetic energy (KE) of wave 1 into APE of wave 1 leads to weakening of wave 1 during CLP2. In case of wave 2, lower rate of conversion of KE to APE leads to stronger wave 2 during CLP2.
\end{abstract}

\section{Introduction}

The Indian monsoon is not a local phenomenon but one of the major components of the global circulation. It interacts with other components of the global circulation in a significant and systematic manner (Pisharoty and Desai 1956; Krishnamurti and Bhalme 1976; Murakami 1976; Sikka and Grey 1981; Bawiskar et al. 2005a, b). Fluctuations in the monsoon are reflections of the fluctuations in the global circulations. Global circulation comprises of planetary scale disturbances having wave-like character. Zonal asymmetry between land and ocean in the tropics plays a dominant role in the dynamics of the tropical atmosphere. During northern summer, the lower tropospheric temperature, pressure, wind direction, humidity, and circulation features over land and oceans show a marked contrast. Lands are warmer than the oceans causing lows over land and highs over ocean while meridional wind is southerly over land and northerly over ocean at lower levels. Lands are humid and oceans are relatively dry. These contrasting features persist throughout northern summer and are mainly responsible for the generation of seasonal/standing eddies. In the northern tropics, the low level jet, heat low over Pakistan, oceanic anticyclones and cyclonic circulations over Indian subcontinent are the major standing eddies which are seen throughout the northern summer in the lower troposphere. Performance of summer monsoon mainly depends upon the intensity of these standing eddies. Intensity of the eddies is directly related to the wind speed or the kinetic

Keywords. Energetics; lower troposphere; wave number two; sensible heat transport; Indian summer monsoon.

J. Earth Syst. Sci. 123, No. 8, December 2014, pp. 1739-1747

(C) Indian Academy of Sciences 
energy and can be quantified through Fourier technique.

Fourier technique is widely used by many investigators (Saltzman 1970; Krishnamurti and Kanamitsu 1981; Murakami 1981; Bawiskar et al. 1989) for the space spectral analysis to study the spectral characteristics of various atmospheric eddies in space domain. The advantage of the Fourier technique is that the observed field gets decomposed into independent components. These components are called harmonics. Space harmonics are called zonal waves while time harmonics are called frequencies. Through space spectral analysis, one can study the energetics of zonal waves and energy exchanges among them.

Global warming is receiving worldwide attention because of its impact on the regional climate. Indian monsoon rainfall activity has changed in many ways. Kothawale et al. (2008) observed that the All India Summer Monsoon Rainfall (AISMR) has decreased at the rate of $1.5 \mathrm{~mm} /$ year. Number of depressions/cyclonic storms during monsoon season has also reduced considerably (Jadhav and Munot 2008) during recent decades. The monsoon circulation has weakened (Bawiskar 2009a). In the present paper, the impact of global warming on the intensity of lower tropospheric ultra-long waves is presented.

\section{Data}

Monthly mean grid point data of zonal wind $(u)$, meridional wind $(v)$ and temperature $(T)$ at $2.5^{\circ}$ latitude $\times 2.5^{\circ}$ longitude grid intervals for the 10 standard pressure levels $(1000,850,700,600,500$, $400,300,200,150$ and $100 \mathrm{hPa}$ ) for the 60-year (1949-2008) period of National Centers for Environmental Prediction/National Center for Atmospheric Research (NCEP/NCAR) reanalysis data (Kalnay et al. 1996) has been considered for the study.

\section{Methodology}

Fourier technique is used to decompose the wind field in spectrum of zonal waves. For example, the zonal wind $u$ is expressed as:

$$
u(\lambda)=\sum_{n=0}^{N / 2}\left(a_{n} \cos \left(\frac{2 \pi n \lambda}{N}\right)+b_{n} \sin \left(\frac{2 \pi n \lambda}{N}\right)\right) .
$$

The Fourier coefficients are computed as follows:

$$
a_{n}=\frac{2}{N} \sum_{\lambda=1}^{N}\left(u(\lambda) \cos \left(\frac{2 \pi n \lambda}{N}\right)\right) ;
$$

$$
b_{n}=\frac{2}{N} \sum_{\lambda=1}^{N}\left(u(\lambda) \sin \left(\frac{2 \pi n \lambda}{N}\right)\right)
$$

where $n$ is the wave number, $\lambda$ is the longitude and $N$ is the number of grid points along a latitude circle. Similarly $\left(c_{n}, d_{n}\right)$ for meridional wind $v$ and $\left(e_{n}, f_{n}\right)$ for temperature $T$ are computed. The Fourier coefficients are used to compute following parameters.

Kinetic energy of zonal wave $n$,

$$
K(n)=\frac{1}{4}\left(a_{n}^{2}+b_{n}^{2}+c_{n}^{2}+d_{n}^{2}\right) .
$$

Sensible heat transport (SHT) by zonal wave $n$,

$$
\operatorname{SHT}(n)=\frac{1}{2}\left(c_{n} e_{n}+d_{n} f_{n}\right) .
$$

From the above equations, kinetic energy and sensible heat transport of the waves 1-10 are computed for the monsoon season (JJAS) of all the 60 years (1949-2008) and for latitudes from equator to $50^{\circ} \mathrm{N}$.

In this paper, we present the results at $850 \mathrm{hPa}$ and also for lower troposphere (Trapezoid-average of 1000,850 and $700 \mathrm{hPa}$ ).

\section{Results and discussion}

\subsection{Dominance of the ultra-long waves}

Figure 1 shows the percentage variance of kinetic energy explained by waves $1-10$ for $10^{\circ} \mathrm{N}$ at (a) $850 \mathrm{hPa}$ and (b) lower troposphere during monsoon season. More than $50 \%$ of variance is explained by wave 1 and wave 2 explains about 20\%. Similar results are also observed for 700 and $1000 \mathrm{hPa}$ and at $12.5^{\circ}$ and $7.5^{\circ} \mathrm{N}$. It is also observed that the distribution of variance almost remains the same with marginal variations from year to year. Total contribution by ultra-long waves is always more than $70 \%$. For active monsoon period it reaches up to $85 \%$ and for weak monsoon period it comes down up to $70 \%$.

\subsection{Contrasting feature of ultra-long waves}

Although, energetics of waves 1 and 2 dominate the wave spectrum, role of individual waves is examined in the study. For this, correlation analysis between the time series of two waves for the 60year period is performed. It is seen that wave 1 and wave 2 are inversely correlated (figure 2). The significant $(\mathrm{CC}>|-0.26|)$ (5\% significant level) area is shaded. During monsoon months, the significant area is located between $12.5^{\circ}$ and $7.5^{\circ} \mathrm{N}$. 

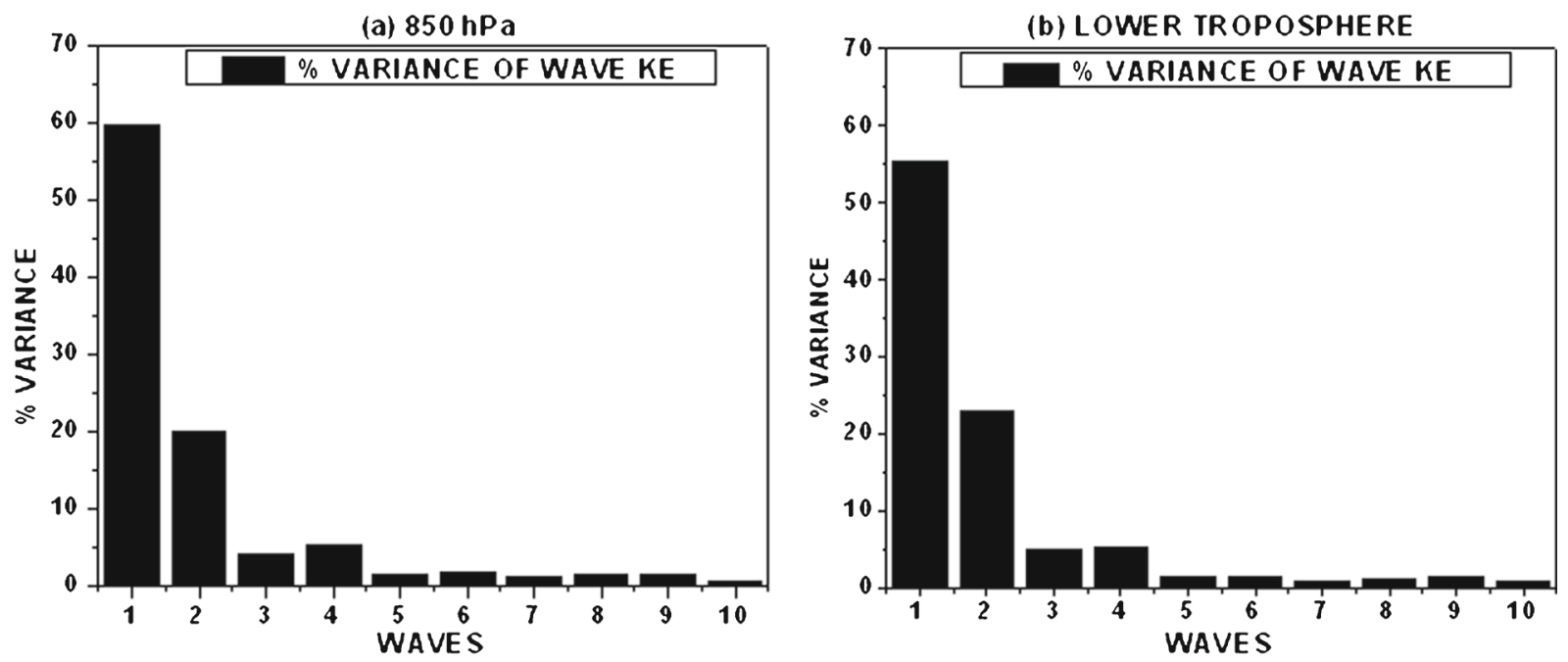

Figure 1. The percentage variance explained by kinetic energy of waves $1-10$ at $10^{\circ} \mathrm{N}$ for (a) $850 \mathrm{hPa}$ and (b) lower troposphere for the seasonal (JJAS) climatology of 60 years (1949-2008).

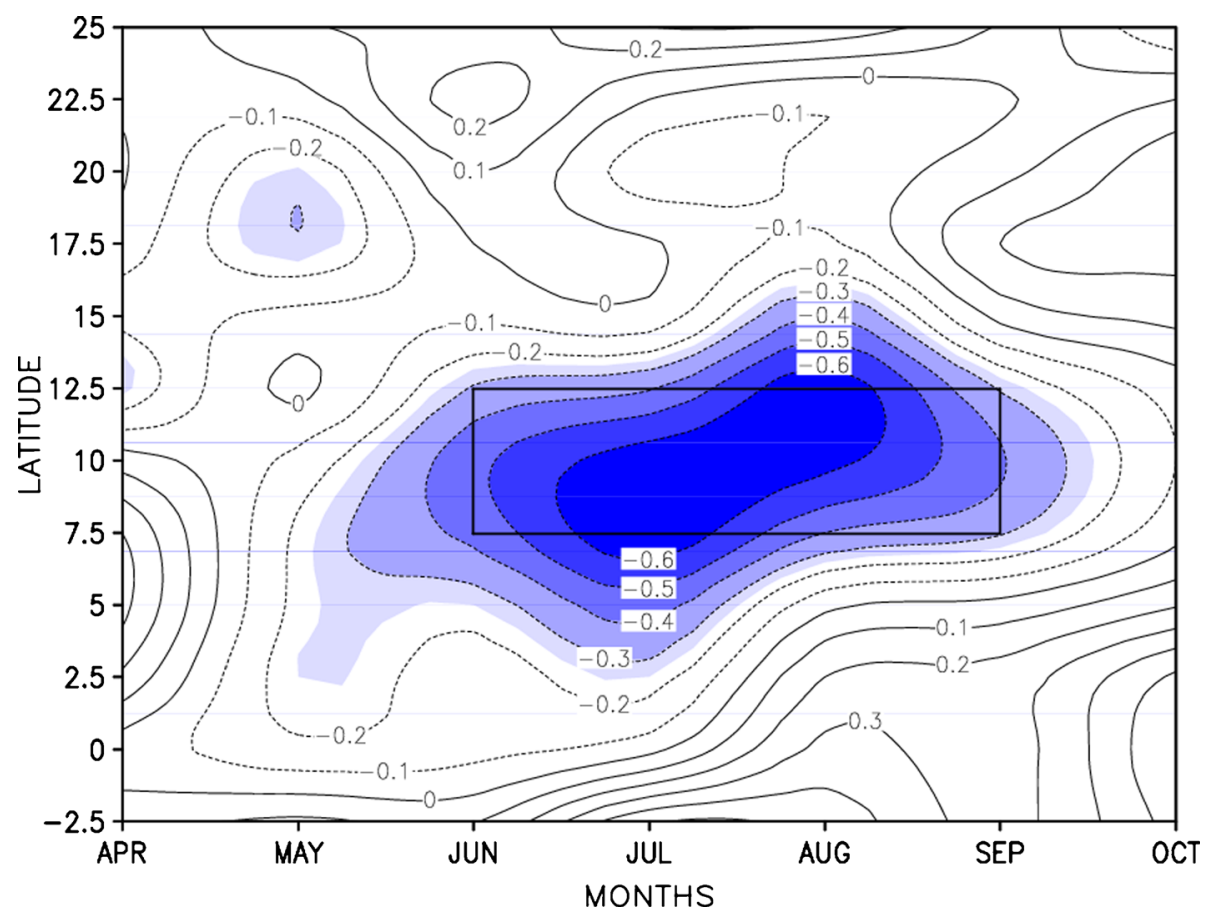

Figure 2. Latitudinal and monthly variations of correlation coefficient between kinetic energy of wave 1 and wave 2 at 850 hPa.

\subsection{Westerly winds and wave 1}

During northern winter, the global belt around $10^{\circ} \mathrm{N}$ is covered by easterlies (figure $3 \mathrm{a}$ ). As the northern summer advances and sets in, the easterlies from $20^{\circ} \mathrm{W}$ to $150^{\circ} \mathrm{E}$ are replaced by westerlies (figure $3 \mathrm{~b}$ ). These westerlies are very strong over Arabian Sea (AS), Indian Land Mass (ILM) and Bay of Bengal (BOB). During the northern summer monsoon season, deep convective zone over $\mathrm{BOB}$ is mainly responsible for the existence of the lower tropospheric westerlies to its west. Stronger westerlies imply intense convective zone and rainfall activity (Joseph 1998). The westerlies over the AS and ILM are the components of Low Level Jet (LLJ) and these influence all India monsoon rainfall (Paul et al. 1990). Cross equatorial flow and low level westerly jet also have significant correlation with Indian summer monsoon rainfall. Bedi et al. (1981) showed that a strong monsoon is associated with strong westerlies and weak monsoon is associated with weak westerlies. Low level westerly 
(a) WINTER SEASON (DJF)

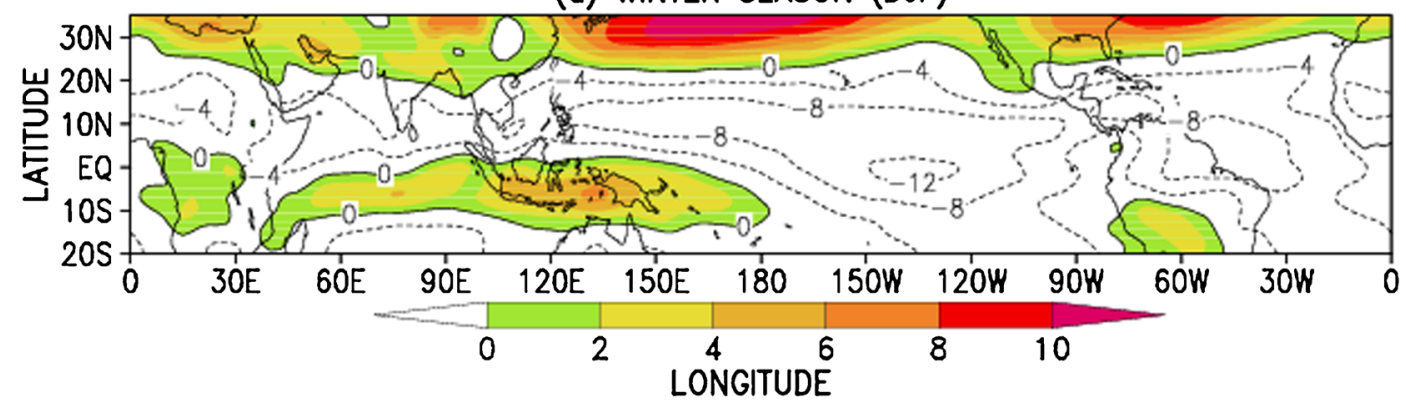

(b) SUMMER SEASON (JJAS)

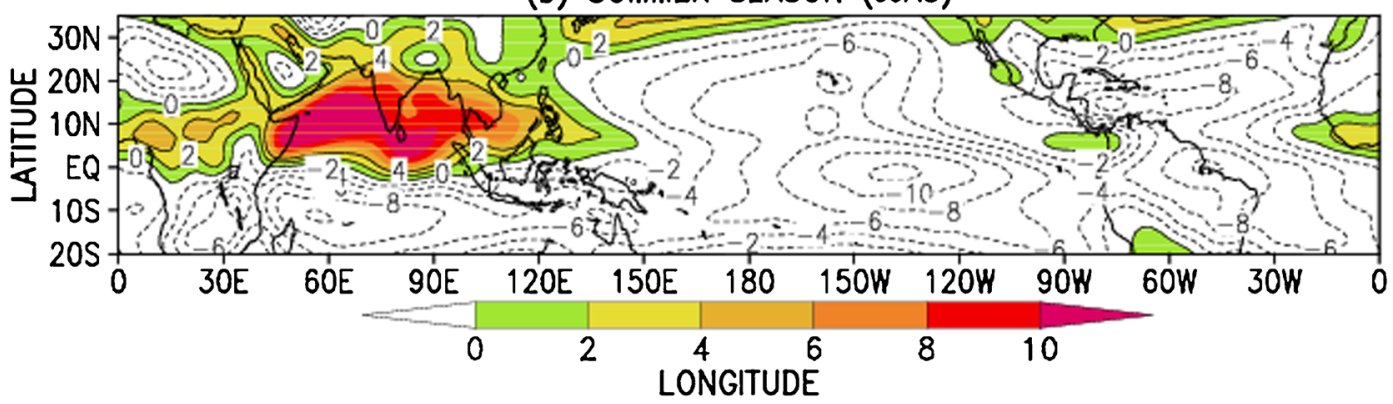

Figure 3. Climatological mean (1949-2008) of zonal wind $(u)\left(\mathrm{ms}^{-1}\right)$ at $850 \mathrm{hPa}$ during (a) northern winter (DJF) and (b) summer (JJAS) seasons.

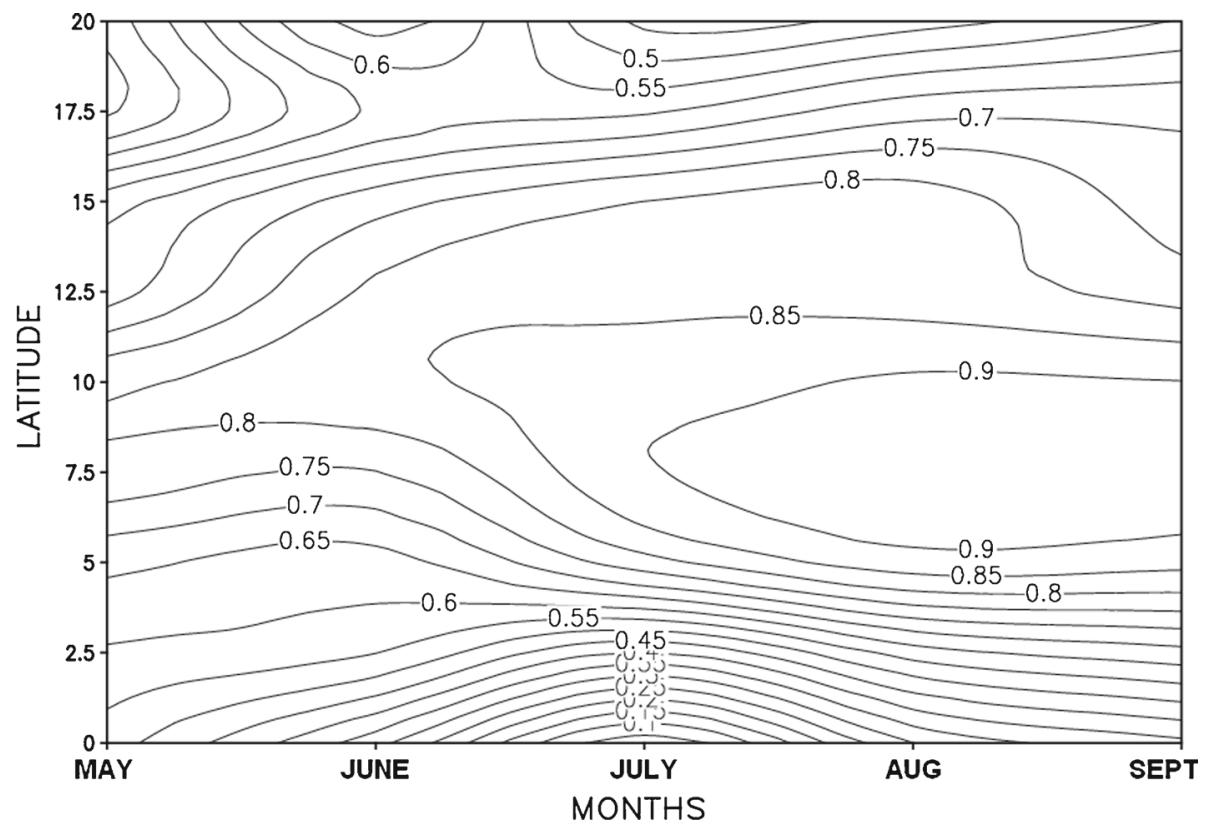

Figure 4. Latitudinal and monthly variations of correlation coefficient between kinetic energy of westerly wind and kinetic energy of wave 1 at $850 \mathrm{hPa}$.

jet is represented by wave 1 on the global scale (Bawiskar et al. 2009b).

Correlation (figure 4) between the kinetic energy of westerly winds (over AS and ILM) and kinetic energy of wave 1 is highly significant (1\% significant level). This indicates that strong westerlies strengthens wave 1 and vice versa.
Bawiskar et al. (2009b) observed a strong significant positive correlation between intensity of wave number 1 and All India Summer Monsoon Rainfall (AISMR) on a daily scale. It is also observed that wave 1 is a major source of kinetic energy to the systems forming over the BOB during monsoon season (Bawiskar et al. 2005a). Thus, wave 1 plays 
a very important role in the energetics of Indian monsoon rainfall activity.

\subsection{Oceanic circulations and wave 2}

Atlantic and Pacific oceans are mainly covered by two distinct anticyclonic circulations (figure 5a). These two distinct anticyclonic circulations are sources of energy to wave 2. Effective strengths of these two isolated and well organised circulations have direct relations with the intensity of wave 2 . Two separated easterly zones (figure 5b) associated with these anticyclonic circulations over the lower tropics mainly contribute to the energetics of wave 2 .

Figure 6 presents observed $u$, its decomposed components wave 1 , wave 2 , and combined effect of waves 1 and 2 at $10^{\circ} \mathrm{N}(850 \mathrm{hPa})$. The region between $20^{\circ} \mathrm{W}$ and $150^{\circ} \mathrm{E}$ is covered by westerlies $(u>0)$ and the region between $150^{\circ}$ and $330^{\circ} \mathrm{E}$ is covered by easterlies $(u<0)$ with two anticylconic circulations. Positive amplitude of wave 1 is over the region of westerlies and negative amplitude of wave 2 is over the region of easterlies.

\subsection{Interannual variation of kinetic energy of ultra-long waves}

The interannual variability of the kinetic energy of waves 1 and 2 at the latitudinal belt averaged for $12.5^{\circ}-7.5^{\circ} \mathrm{N}$ is presented in figure $7(\mathrm{a}, \mathrm{b})$. It is clearly seen that the kinetic energy of the wave 1 has a decreasing trend (figure 7a) and kinetic energy of wave 2 shows an increasing trend (figure $7 \mathrm{~b}$ ). Correlation coefficient between these two series is -0.74 (1\% significant level).

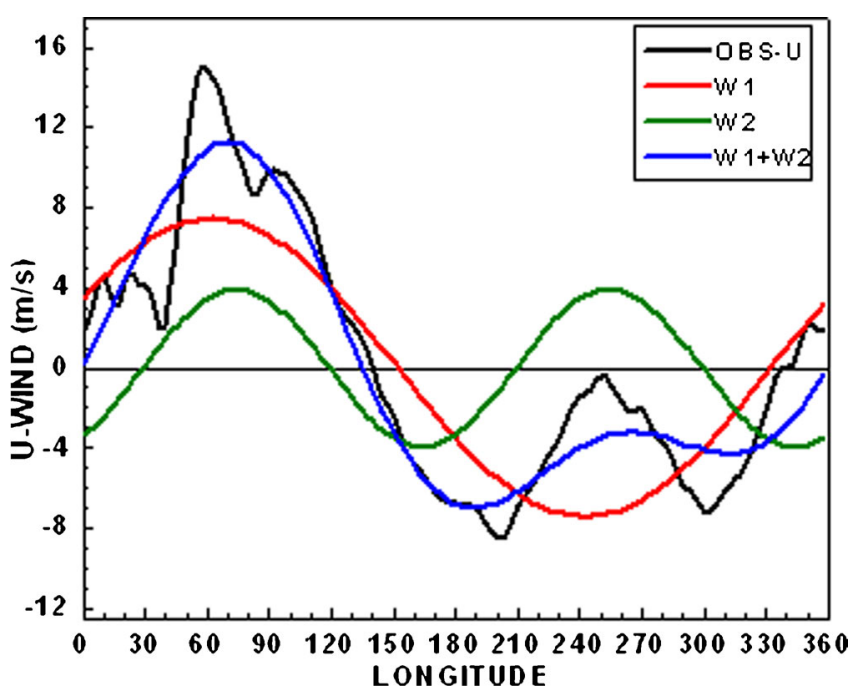

Figure 6. Longitudinal variations of observed $u$, wave 1 , wave 2 and resultant of waves 1 and 2 at $10^{\circ} \mathrm{N}(850 \mathrm{hPa})$ for the seasonal (JJAS) climatology of 60 years (1949-2008) $\left(\mathrm{ms}^{-1}\right)$.

(a) STREAM LINES

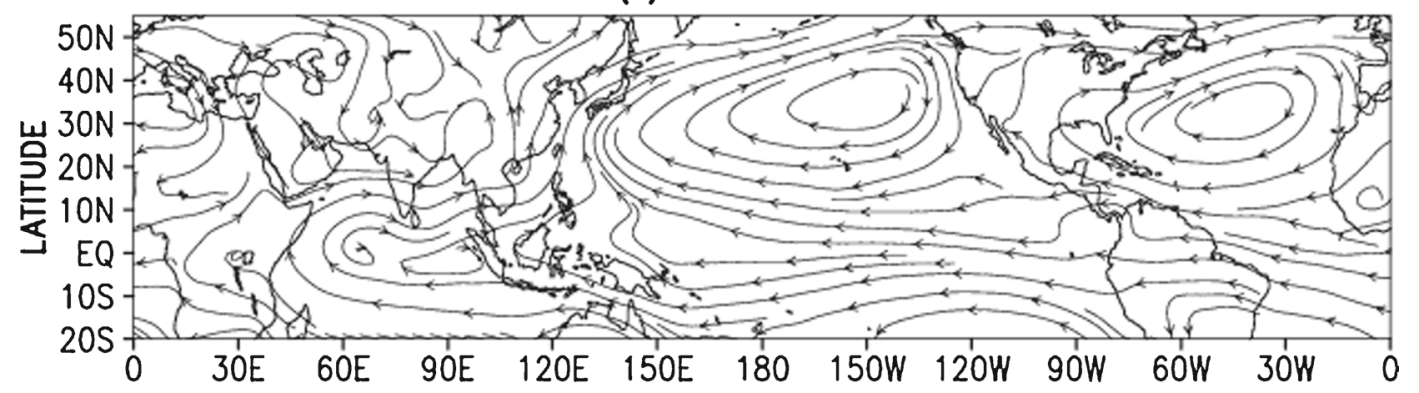

(b) WIND VECTOR

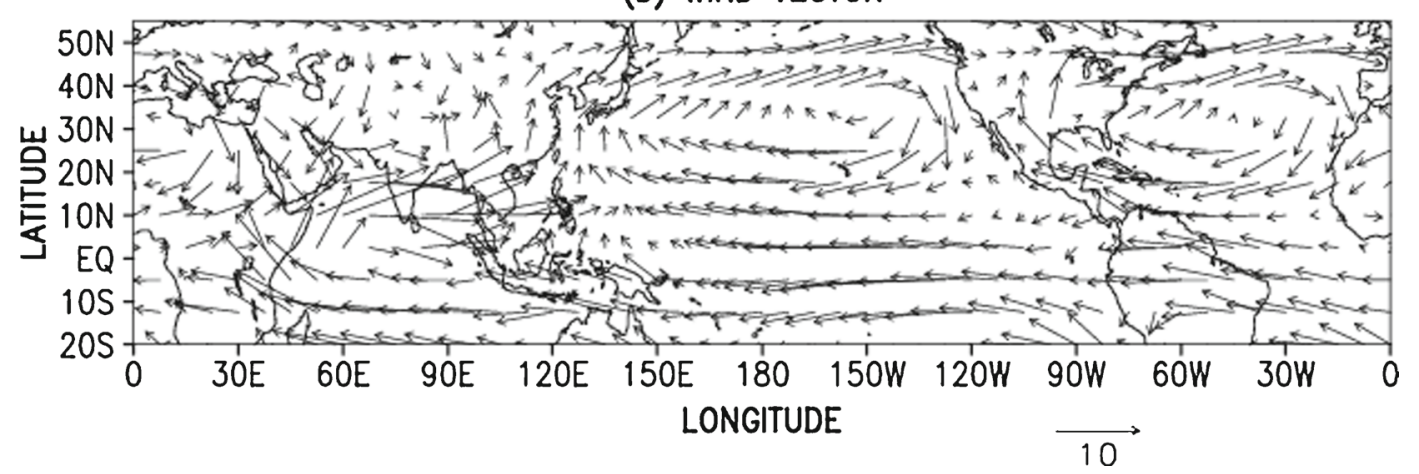

Figure 5. Seasonal (JJAS) climatology of 60 years (1949-2008) of (a) stream line and (b) wind vector ( ms $^{-1}$ ) fields at $850 \mathrm{hPa}$. 
(a) WAVE 1

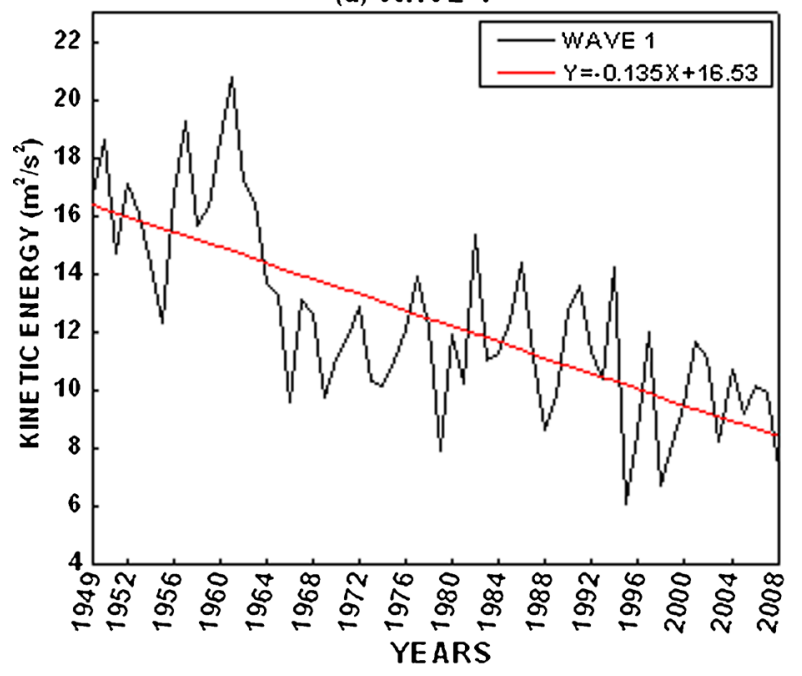

(b) WAVE 2

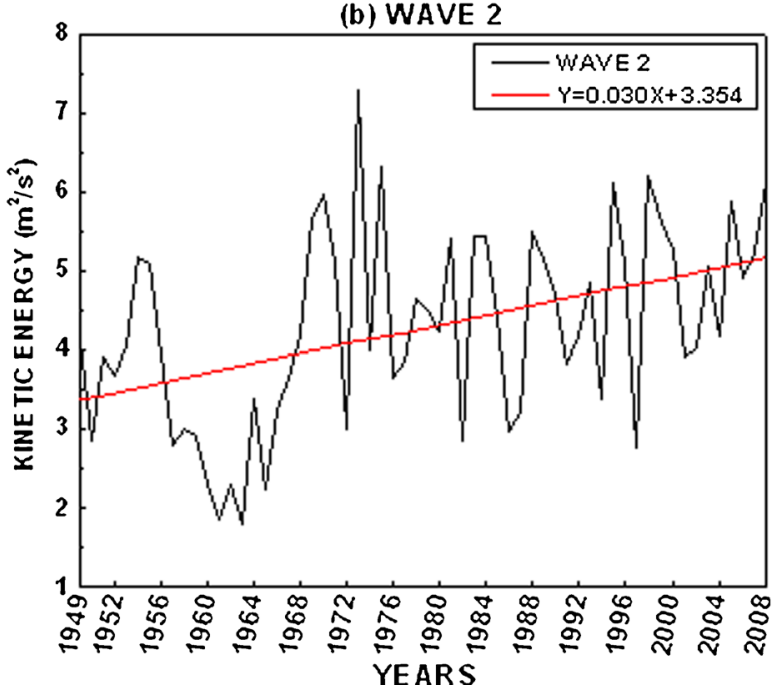

Figure 7. Interannual variations of the lower tropospheric kinetic energy $\left(\mathrm{m}^{2} \mathrm{~s}^{-2}\right)$ of (a) wave 1 and (b) wave 2 averaged for latitudinal belt $\left(12.5^{\circ}-7.5^{\circ} \mathrm{N}\right)$ during monsoon season (JJAS).

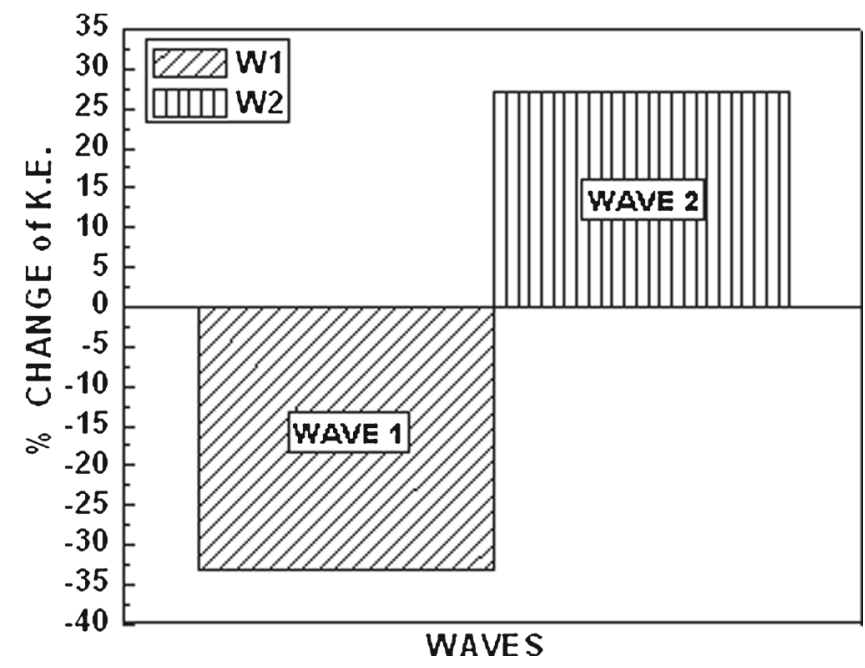

Figure 8. Percentage change of kinetic energy of waves 1 and 2 for two climatic periods (i) CLP1 and (ii) CLP2 at $10^{\circ} \mathrm{N}$ during monsoon season (JJAS) (850 hPa).

\subsection{Climatic change of energetics of ultra-long waves}

Percentage change of kinetic energy of ultra-long waves for two climatic periods (i) CLP1 and (ii) CLP2 indicates that wave 1 has weakened by about $33 \%$ while wave 2 is strengthened by about $27 \%$ (figure 8). It shows that the strengthening of wave 2 weakens wave 1 .

\subsection{Cause and effect of strengthening of wave 2}

Two anticyclonic circulations, over (i) mid-Pacific and (ii) mid-Atlantic ocean are mainly responsible for the second largest contribution by wave 2 .
In view of this, the air temperature (lower troposphere) during summer monsoon season (JJAS) are averaged for Pacific $\left(40^{\circ}-10^{\circ} \mathrm{N} ; 150^{\circ}-225^{\circ} \mathrm{E}\right)$ (figure 9a) and Atlantic $\left(40^{\circ}-10^{\circ} \mathrm{N} ; 300^{\circ}-330^{\circ} \mathrm{E}\right.$ ) oceanic regions (figure $9 \mathrm{~b}$ ). Air temperatures over both the oceanic areas increased significantly $(5 \%$ significant level). Student's t-test shows that the change in the air temperature over the lower troposphere for CLP1 and CLP2 is significant at 1\% significant level. The increase of air temperature over both the oceanic areas might be the cause of intensification of wave 2 .

Interannual variation of the transport of sensible heat by wave 2 during the period 1949-2008 is shown in figure 10. Positive (negative) sign indicates northward (southward) transport of sensible heat. Interannual variation of sensible heat transport by wave 2 is positive during CLP1 and negative during CLP2.

Phase variations of the wave 2 for meridional $(v)$ wind and temperature $(T)$ at $10^{\circ} \mathrm{N}$ during the two climate episodes at $850 \mathrm{hPa}$ (figure 11a, b) has interesting features and is one of the best observed feature of the climate change during the last 60 years (1949-2008). Phase of wave 2 in the $v$-field shifts by about $40^{\circ}$ towards east and phase of wave 2 in temperature field shifts by $20^{\circ}$ towards west during CLP2. Thus, in phase waves during CLP1 become out of phase during CLP2. Because of this climatic change, the northward transport of sensible heat by wave 2 during CLP1 turns into southward transport during CLP2. Over Indian region, the phases of $v$ and $T$ of wave 2 during CLP1 are almost similar indicating northward transport of sensible heat. It means that over ILM, warm air is advected towards north. This causes an 

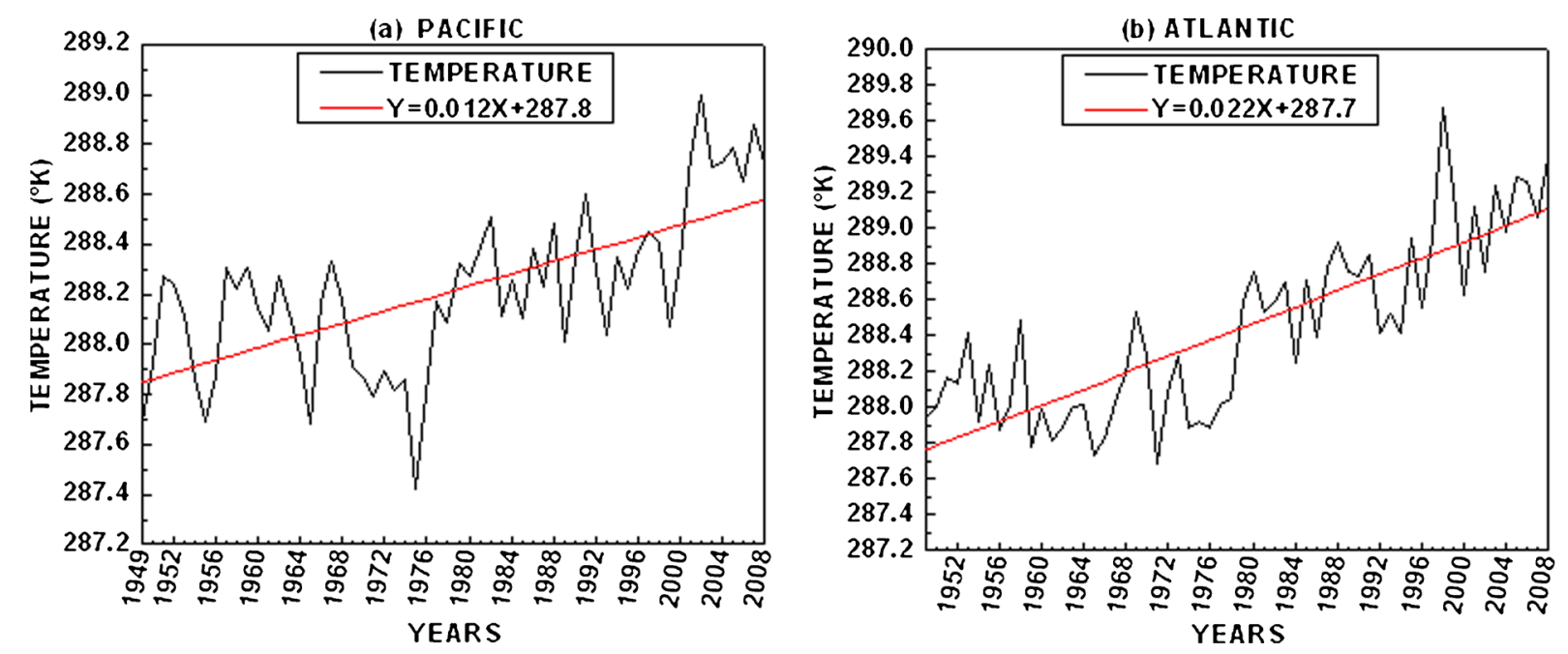

Figure 9. Interannual variations of the lower tropospheric air temperature (K) during monsoon season (JJAS) for the (a) Pacific $\left(40^{\circ}-10^{\circ} \mathrm{N} ; 150^{\circ}-225^{\circ} \mathrm{E}\right)$ and (b) Atlantic $\left(40^{\circ}-10^{\circ} \mathrm{N} ; 300^{\circ}-330^{\circ} \mathrm{E}\right)$ oceanic regions.

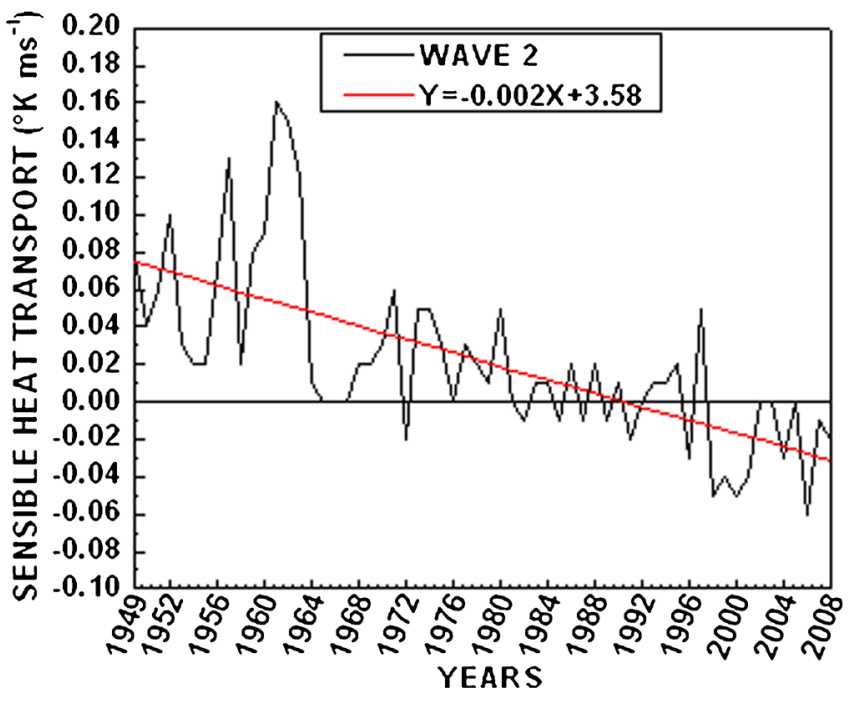

Figure 10. Interannual variation of sensible heat transport $\left(\mathrm{K} \mathrm{ms}^{-1}\right)$ by wave 2 at $850 \mathrm{hPa}$ for $10^{\circ} \mathrm{N}$ during monsoon season (JJAS).

increase in the north-south (NS) temperature gradient. Increase of NS temperature gradient leads to strengthening of cross-equatorial flow. Stronger cross-equatorial flow increases the moisture incursion over Indian landmass. As mentioned earlier, cross equatorial flow and low level westerly winds have significant correlation with Indian summer monsoon rainfall. As such, over the Indian region, the northward sensible heat transport by wave 2 strengthens wave 1 . It is not observed for CLP2, since the phases of $v$ and $T$ over Indian region are almost in opposite direction. During CLP2, southward sensible heat transport is seen over oceanic regions.

\subsection{Energy generation and conversion}

Energy generation (G) and conversion (C) processes are evaluated by computing corresponding terms of energy equations in the domain of wave number. The complete equations and their physical meaning used in the study are given in Saltzman (1970). Table 1 shows the seasonal energy components at $850 \mathrm{hPa}$ around the $10^{\circ} \mathrm{N}$. The table presents the contributions of waves 1 and 2 along with the zonal mean flow (wave 0). Our results differ in magnitude and direction with the results of Saltzman (1970) and Kanamitsu (1981) because our results are based on $850 \mathrm{hPa}$ data for summer season (JJAS) whereas their results are based on upper troposphere (200-300 hPa) data and for different periods and latitudinal belts. Further, the circulation patterns of lower troposphere $(850 \mathrm{hPa})$ and upper troposphere $(200,300 \mathrm{hPa})$ are opposite.

\subsubsection{Generation of available potential energy (APE), G(n)}

Zonal differential heating due to land and ocean around $10^{\circ} \mathrm{N}$ in the lower troposphere during northern summer is mainly responsible for the generation of zonal mean APE, $G(0)$. The magnitude of $G(0)$ is larger for CLP2 indicating more nonadiabatic heating during CLP2. Negative sign of $G(1)$ during both the CLP1 and CLP2 periods represents cooling process of the atmosphere. The contributions by $G(2)$ are small and positive for both the periods CLP1 and CLP2. Though they are small, the $G(2)$ for CLP2 is more than for 

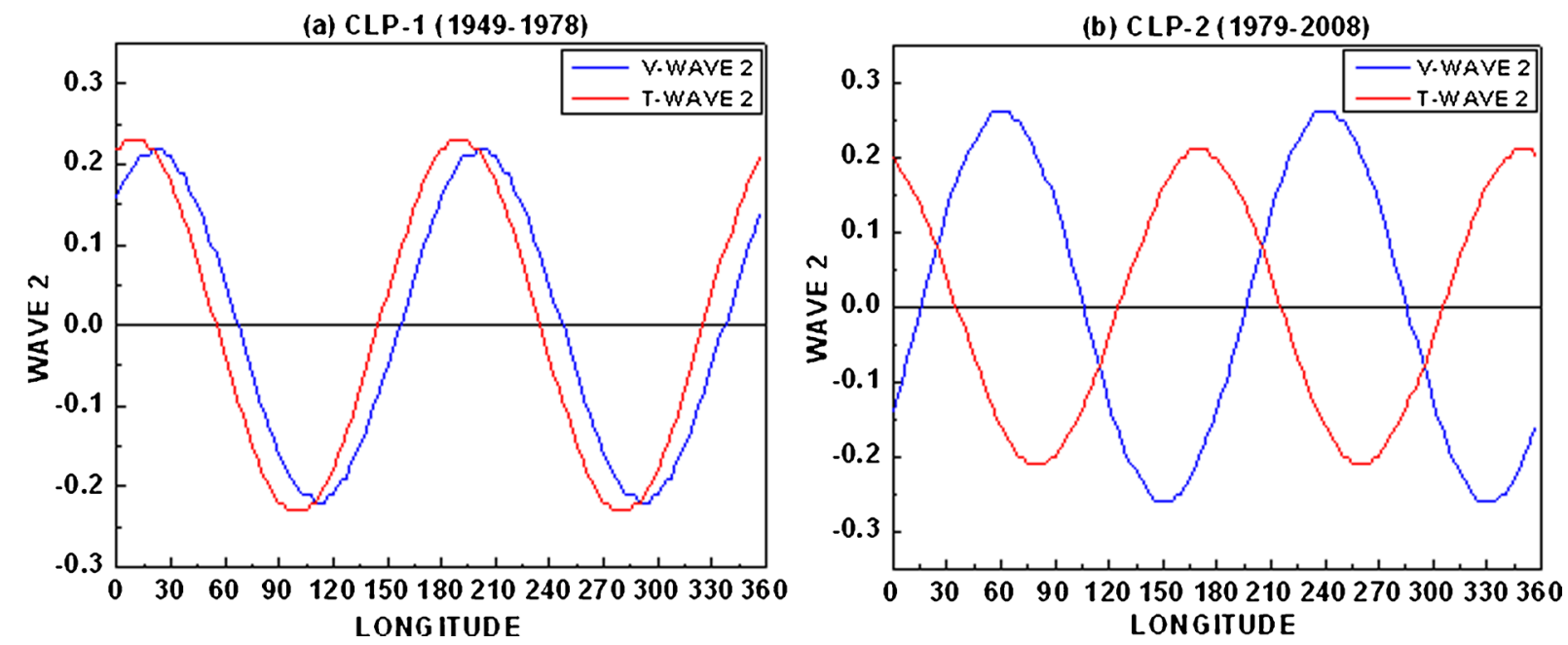

Figure 11. Phase variations of wave 2 for meridional wind $(v)$ and temperature $(T)$ at $10^{\circ} \mathrm{N}(850 \mathrm{hPa})$ during seasonal (JJAS) climatic periods (a) CLP1 (1949-1978) and (b) CLP2 (1979-2008).

Table 1. Generation $(G)$, available potential energy $(P)$, conversion $(C)$ and kinetic energy $(K)$ of zonal mean flow (wave 0), wave 1 and wave 2 at $10^{\circ} \mathrm{N}(850 \mathrm{hPa})$ during Indian summer monsoon season (JJAS) for two climatic periods CLP1 and CLP2 (unit: $\mathrm{m}^{2} \mathrm{~s}^{-2}$ for $P$ and $K ; 10^{-5} \mathrm{~m}^{2} \mathrm{~s}^{-3}$ for conversions).

\begin{tabular}{|c|c|c|c|c|c|c|c|c|}
\hline \multirow[b]{2}{*}{ Wave $(n)$} & \multicolumn{2}{|c|}{$G(n)$} & \multicolumn{2}{|c|}{$P(n)$} & \multicolumn{2}{|c|}{$C(n)$} & \multicolumn{2}{|c|}{$K(n)$} \\
\hline & $\overline{\text { CLP1 }}$ & CLP2 & $\overline{\text { CLP1 }}$ & CLP2 & $\overline{\text { CLP1 }}$ & CLP2 & $\overline{\text { CLP1 }}$ & $\overline{\text { CLP2 }}$ \\
\hline 0 & 40.33 & 47.08 & 9.89 & 9.01 & 2.68 & 2.61 & 0.47 & 0.40 \\
\hline 1 & -1.95 & -3.00 & 4.15 & 6.97 & -2.84 & -5.62 & 17.45 & 11.30 \\
\hline 2 & 0.05 & 0.13 & 0.11 & 0.09 & -0.41 & -0.34 & 3.25 & 4.48 \\
\hline
\end{tabular}

Note. $n$ : wave number; $G>0$ : rate of generation of APE due to nonadiabatic heating (unit: $10^{-5} \mathrm{~m}^{2} \mathrm{~s}^{-3}$ ) ; $G<0:$ rate of dissipation of APE due to nonadiabatic cooling (unit: $10^{-5} \mathrm{~m}^{2} \mathrm{~s}^{-3}$ ); $P$ : total APE (unit: $\mathrm{m}^{2} \mathrm{~s}^{-2}$ ); $C>0:$ rate of conversion of APE to kinetic energy (unit: $10^{-5} \mathrm{~m}^{2} \mathrm{~s}^{-3}$ ) $; C<0$ : rate of conversion of kinetic energy to APE (unit: $10^{-5}$ $\mathrm{m}^{2} \mathrm{~s}^{-3}$ ) and $K$ : kinetic energy (unit: $\mathrm{m}^{2} \mathrm{~s}^{-2}$ ).

CLP1 which results into the strengthening of wave 2 during CLP2.

\subsubsection{Total APE, $P(n)$}

APE of zonal flow, $P(0)$ for both the periods are almost same in magnitude whereas $P(1)$ for CLP2 is nearly 1.5 times higher and contribution by $P(2)$ is very small.

\subsubsection{Conversion of APE to KE of wave $n, C(n)$}

During both the climatic periods, $C(0)$ are almost same in magnitude and the positive direction indicates that zonal APE is converted into zonal kinetic energy, $K(0)$. In case of $C(1)$, direction of flow is opposite, i.e., kinetic energy of wave 1 is converted to $P(1)$ and during CLP2, this rate is almost double and that is why we find the significant decrease of $K(1)$ during CLP2. $C(2)$ also supplies energy to $P(2)$ but during CLP2 the rate is slower and that is why we find stronger $K(2)$ during CLP2.

\section{Conclusions}

From the analysis of monthly and seasonal energetics of the zonal waves, following conclusions can be made:

- Ultra-long waves (waves 1 and 2) dominate the spectrum of zonal waves with more than $50 \%$ contribution by wave 1 and $20 \%$ contribution by wave 2 .

- During monsoon season, strong westerlies over Indian subcontinent are the source of energy to wave 1 and two anticyclonic circulations (over Pacific and Atlantic oceans) are the sources of energy to wave 2.

- Interannual variation of the kinetic energy of waves 1 and 2 shows that wave 1 is weakening and strength of wave 2 is increasing.

- Analysis of two climatic episodes of CLP1 and CLP2 shows that wave 1 has weakened by about $33 \%$ and intensity of wave 2 has increased by about $27 \%$ during CLP2. 
- Significant increasing trends of temperatures over mid-Pacific and mid-Atlantic oceanic regions might be the cause of strengthening of wave 2.

- Northward transport of sensible heat by wave 2 strengthens the meridional temperature gradient over the Indian region and helps to maintain the strength of westerlies and wave 1 during monsoon season in CLP1. As the transport of sensible heat by wave 2 changes into southward direction, it weakens the north-south temperature gradient over the Indian landmass and also monsoon circulation during CLP2.

- Larger generation of zonal mean available potential energy (APE) during CLP2 indicates more heating. A larger conversion of $\mathrm{KE}$ of wave 1 into APE of wave 1 leads to weakening of wave 1 during CLP2. In case of wave 2, lower rate of conversion of $\mathrm{KE}$ to $\mathrm{APE}$ leads to stronger wave 2 during CLP2.

\section{Acknowledgements}

The authors are thankful to Prof. B N Goswami, Director, Indian Institute of Tropical Meteorology, Pune for his keen interest in the study. The authors are also grateful to Dr A K Sahai, Chief Project Scientist, Model Development and Prediction Extended Range Prediction, Indian Institute of Tropical Meteorology, Pune for the encouragement.

\section{References}

Bawiskar S M, Awade S T and Singh S S 1989 Harmonic analysis of summer wind at $200 \mathrm{mb}$ level during contrasting monsoon years over India; Proc. Indian Acad. Sci. (Earth Planet. Sci.) 98(4) 365-373.

Bawiskar S M, Chipade M D, Mujumdar V R, Bhide U V and Singh S S 2005a Contrasting features of wave number one during northern summer monsoon seasons of 1997 and 2002; Mausam 56(2) 337-342.

Bawiskar S M, Chipade M D, Mujumdar V R, Puranik P V and Bhide U V 2005b Kinetic energy of extra-tropical waves and their effect on the Indian monsoon rainfall; Mausam 56(3) 681-685.

Bawiskar S M 2009a Weakening of lower tropospheric temperature gradient between Indian land mass and neighbouring oceans and its impact on Indian monsoon; J. Earth Syst. Sci. 118(4) 273-280.
Bawiskar S M, Chipade M D and Puranik P V 2009b Energetics of lower tropospheric ultra-long waves: A key to intra-seasonal variability of Indian monsoon; J. Earth Syst. Sci. 118(2) 115-121.

Bedi H S, Billa H S and Mukarjee N 1981 Interaction between northern middle latitude and summer monsoon circulation; Int. Conf. on early results of FGGE and large scale aspects of monsoon experiment GARP, Tallahassee, Florida, pp. 5-25-5-29.

Jadhav S K and Munot A A 2008 Warming SST of Bay of Bengal and decrease in formation of cyclonic disturbances over Indian region during southwest monsoon season; Theor. Appl. Clim. 96(3-4) 327-336, doi: 10.1007/s00704-008-00434-3.

Joseph P V 1998 Introduction to meteorology; Lecture Notes, unit: 1 Module: 1.1, Published by Space Application Centre, Indian Space Research Organisation, Ahmedabad.

Kalnay E, Kanamitsu M, Kistler R, Collins W, Deaven W, Gandin L, Iredell M, Saha S, White G, Woollen J, Zhu Y, Leetmaa A, Reynolds R, Chelliah M, Ebisuzaki W, Higgins W, Janowiak J, Mo K C, Ropelewski C, Wang J, Jenne R and Joseph D 1996 The NCEP/NCAR 40-year reanalysis project; Bull. Am. Meteor. Soc. 77 437-471.

Kanamitsu M 1981 Analysis of monsoonal quasi-stationary systems as revealed in a real-data prediction experiment; In: Monsoon dynamics (eds) Sir James Lighthill and Pearce R P, Cambridge University Press, pp. 147-164.

Kothawale D R, Munot A A and Borgaonkar H P 2008 Temperature variability over the Indian Ocean and its relationship with Indian summer monsoon rainfall; Theor. Appl. Climatol. 9 31-45.

Krishnamurti T N and Bhalme H N 1976 Oscillations of a monsoon system: Part I. Observational aspects; J. Atmos. Sci. 33 1937-1954.

Krishnamurti T N and Kanamitsu M 1981 Northern summer planetary scale monsoon during drought and normal rainfall months; In: Monsoon dynamics (eds) Sir James Lighthill and Pearce R P, Cambridge University Press, pp. 19-48.

Murakami T 1976 Cloudiness fluctuations during the summer monsoon; J. Meteor. Soc. Japan 54 175-181.

Murakami T 1981 Summer mean energetics for standing and transient eddies in wave number domain; In: Monsoon dynamics (eds) Sir James Lighthill and Pearce R P, Cambridge University Press, pp. 65-80.

Paul D K, Mujumdar V R, Puranik P V, Ghanekar S P, Deshpande V R and Sikka D R 1990 Fluctuations of regional scale atmospheric features in relation to monsoon activities; Mausam 41(2) 309-314.

Pisharoty P R and Desai B N 1956 Western disturbances and Indian weather; Indian J. Met. Geophys. 74 333-338.

Saltzman B 1970 Large-scale atmospheric energetics in the wave number domain; Rev. Geophys. Space Phys. 8 289-302.

Sikka D R and Grey W M 1981 Cross-hemispheric actions and the onset of the summer monsoon over India; Int. Conf. on Sci., Results of monsoon experiments, Bali, Indonesia 26-30 Oct., pp. 3.74-3.78. 